\title{
CRÓNICA DE UN OBJETO PATRIMONIALIZADO: EL CASO DE LAS MURALLAS DE MONTEVIDEO ${ }^{(*)}$
}

\section{CHRONICLE OF A HERITAGE OBJECT: THE CASE OF THE MONTEVIDEO WALLS}

\author{
ADRIANA CAREAGA ALONZO ${ }^{[\star]}$ \\ Fecha de recepción: 15 de setiembre de 2016 \\ Fecha de aprobación: 05 de abril de 2018
}

\begin{abstract}
RESUMEN
Desde tiempos inmemoriales el ser humano ha desarrollado estrategias de defensa de sus bienes materiales, que dan cuenta de las creencias que los sustentan y que en cierta forma han marcado el devenir histórico de sus pueblos. Por ello, para comprender el pasado de un grupo humano es necesario conocer las líneas de pensamiento que han desarrollado sus defensas. El caso que se presenta a continuación corresponde al sistema fortificado de la época colonial de la ciudad de Montevideo, más específicamente el llamado frente de tierra, puntualmente el objeto muralla y el proceso que ha atravesado desde ser invisible para la comunidad hasta tornarse en monumento histórico nacional. Se describe el proceso de recuperación de un lienzo de 13 metros de muralla, situado en un terreno privado, donde funcionó hasta la segunda mitad del siglo XX una antigua fábrica de anilinas. A través de la puesta en valor este se convirtió en un espacio cultural llamado Al Pie de la Muralla, dedicado a la educación patrimonial desde su inauguración en 2004, destinado tanto a las jóvenes generaciones como a las mayores.
\end{abstract}

\section{PALABRAS CLAVE}

Patrimonio, turismo cultural, fortificaciones, muralla, educación patrimonial

\begin{abstract}
Since time immemorial, human beings have developed defense strategies for their material goods, which account for the beliefs that sustain them and which, in a certain way, have marked the historical development of their peoples. Therefore, to understand the past of a group of human beings it is necessary to know the lines of thinking that have developed their defenses. The case study presented below involves the fortified colonial system of the city of Montevideo, more specifically the so-called "land front", punctually the wall object and its transformation from an invisible object for the community to a national historic monument. We describe the recovery process of a canvas of 13 meters of the wall, located in private land, where an old factory of anilines was operative until the second half of the twentieth century. Through a process of valuation, it became a cultural space called "At the Foot of the Wall" dedicated to heritage education since its opening in 2004, intended for both younger and older generations.
\end{abstract}

\section{KEYWORDS}

Heritage, cultural tourism, fortifications, wall, heritage education

$\left(^{*}\right)$ La presente publicación es producto de una de las líneas de investigación personal de auspicio propio, y constituye un esfuerzo más que se suma a los que desde hace más de 15 años viene llevando a cabo la autora del presente artículo por analizar y hacer conocer desde la educación patrimonial -formal y no formal-el patrimonio militar y fortificado de Uruguay, con especial énfasis en Muralla de Montevideo.

$\left(^{* *}\right)$ Profesora de Historia, licenciada en Educación, magíster en Políticas Públicas, directora del espacio cultural Al Pie de la Muralla. Vicepresidente del Consejo Científico Internacional de Fortificaciones (ICOFORT). Contacto: adricareaga@gmail.com 


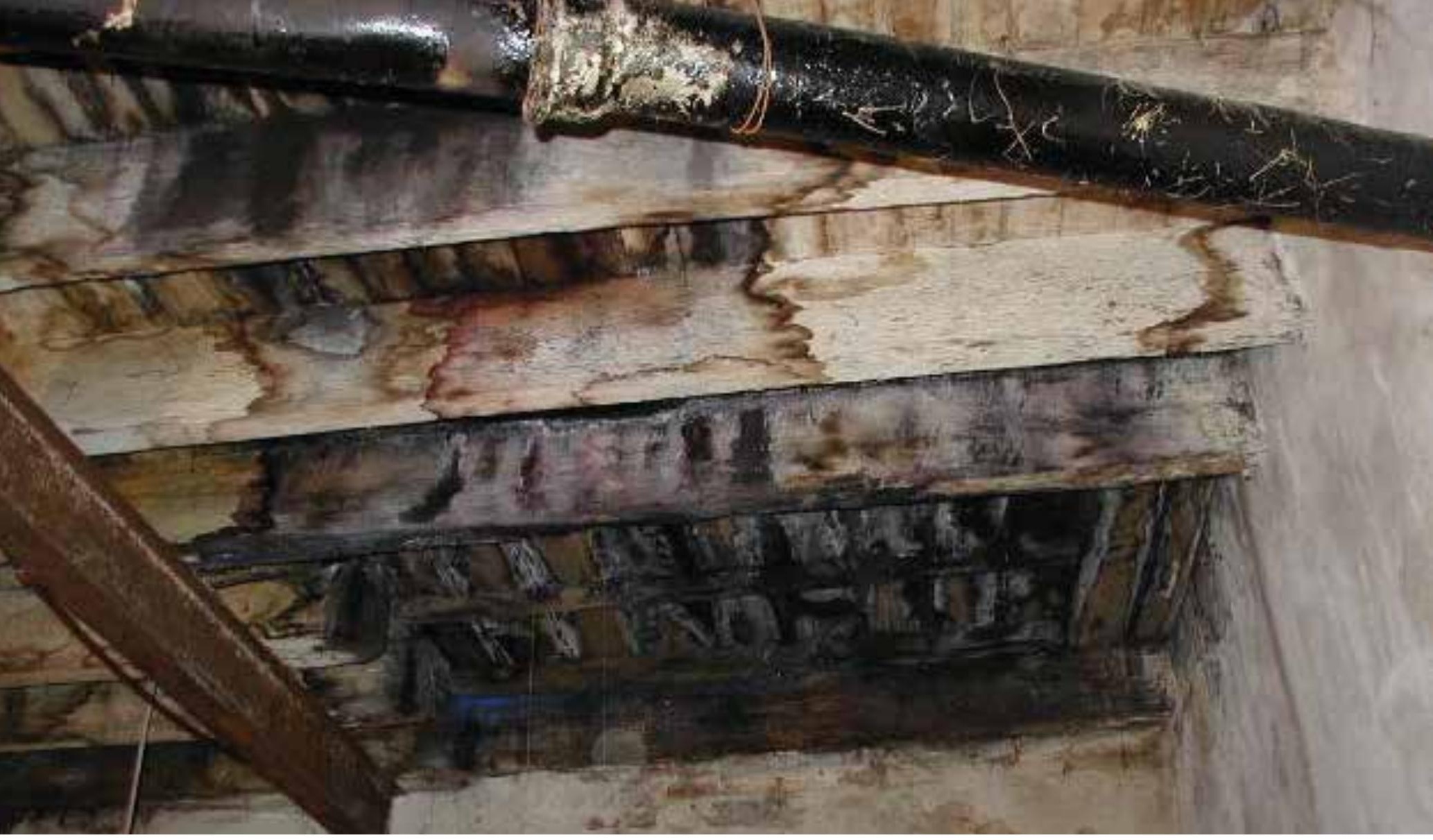

Figura 1. Estado inicial de AI Pie de la Muralla, antes de la puesta en valor. Archivo fotográfico de la autora, 2016.

\section{Hacer visibles los lienzos de muralla}

Montevideo, a diferencia de Cartagena de Indias, no es perceptible hoy como una antigua ciudad amurallada, pues los vestigios de su pasado yacen en su subsuelo, poco explorados. Por lo tanto, los restos del antiguo trazado pasan inadvertidos para el morador y, más aún, para el visitante. El único ícono ciudadano del pasado colonial lo constituye la puerta de la ciudadela, ubicada en la Plaza Independencia, espacio público central y punto neurálgico actual asociado al emplazamiento de la sede del Poder Ejecutivo.

Por otra parte, quedan vestigios del frente de tierra esparcidos en la trama urbana, que no permiten dar cuenta de la totalidad del mismo, lo cual dificulta conceptualizar la antigua plaza fuerte. En la actualidad, se ha llegado a naturalizar un conjunto de piedras dispuestas en muro como parte del paisaje urbano, sin una conceptualización cabal de su importancia en el pasado. Eso representa un problema, pues, en el ámbito de la conservación patrimonial, una premisa conocida es que no se puede preservar lo que no se conoce.

Para comprender cómo un objeto "invisible" y en gran medida ignorado se puede convertir en monumento histórico nacional, es necesario narrar el transcurrir de dicho proceso patrimonializador. En 2002 la Distribuidora Careaga de diarios y revistas adquirió un local en el casco histórico montevideano, conocido como Ciudad Vieja. El local constaba de un gran galpón de dos niveles y un lugar destinado para oficinas. Allí funcionaba hasta la segunda mitad del siglo XX una fábrica de anilinas. Cuando se estaban demoliendo las estructuras existentes a nivel del subsuelo, se realizó un descubrimiento que cambió el curso del proyecto: al picar el revoque de una pared de 13 metros quedó al descubierto un muro de piedra sobre el cristalino del terreno natural (Figura 1).

En ese momento llegó a las manos de los dueños del local un libro editado a fines de la década de los 90 del siglo XX, que daba cuenta de un exhaustivo trabajo de relevamiento de los restos de fortificaciones en Montevideo, realizado por el investigador Raúl Baroffio Burastero (1994), quien detectó un total de 341.70 metros de vestigios arquitectónicos supervivientes, ubicados en predios públicos y privados. El trabajo de Baroffio contenía un mapa que superponía el antiguo trazado del frente de tierra, que 
consistía en una doble muralla, escarpa y contraescarpa, con el foso correspondiente, y el trazado actual de Montevideo (Figura 2).

Analizando el mapa se comprobó que el predio estaba situado cerca del antiguo portón de San Pedro, principal entrada a la ciudad colonial, y que el lienzo de muralla hallado correspondía a la antigua muralla del Montevideo colonial.

El estudio de arquitectos Crocco-Lacroix, que llevó a cabo el trabajo de puesta en valor, constató la existencia de dos zonas perfectamente definidas, con características dispares. Al frente, se encontraban escritorios en dos niveles, sobre una construcción de principios del siglo XX que había sido objeto de reformas (en el año 1940 y una posterior, muy significativa, en 1976), y que presentaba buenas condiciones de estabilidad y habitabilidad. En la zona posterior del predio, estaba ubicado un galpón de 10x12 metros, construido en los años 40 con techo de fibrocemento sobre tirantería de madera, cuyo vestuario y baño habían sido edificados en 1976, cuando se reformó la propiedad por segunda vez.

La característica principal de esta zona posterior era la existencia de un subsuelo con dos amplios locales, separados por una gruesa pared y con un vano de comunicación entre ellos, edificaciones tal vez de fines del siglo XIX o principios del XX. A estos espacios se accedía mediante una escalera de hormigón armado, construida presumiblemente durante la reforma del año 1976. Los techos de los dos locales, que constituyen el piso del
Figura 2. El trazado colonial de las murallas sobre la trama de la actual de la ciudad de Montevideo. En "E Rescate de las Murallas de Montevideo", por R. Baroffio Burastero, 1994. Apartado del Boletín Histórico del Ejército.

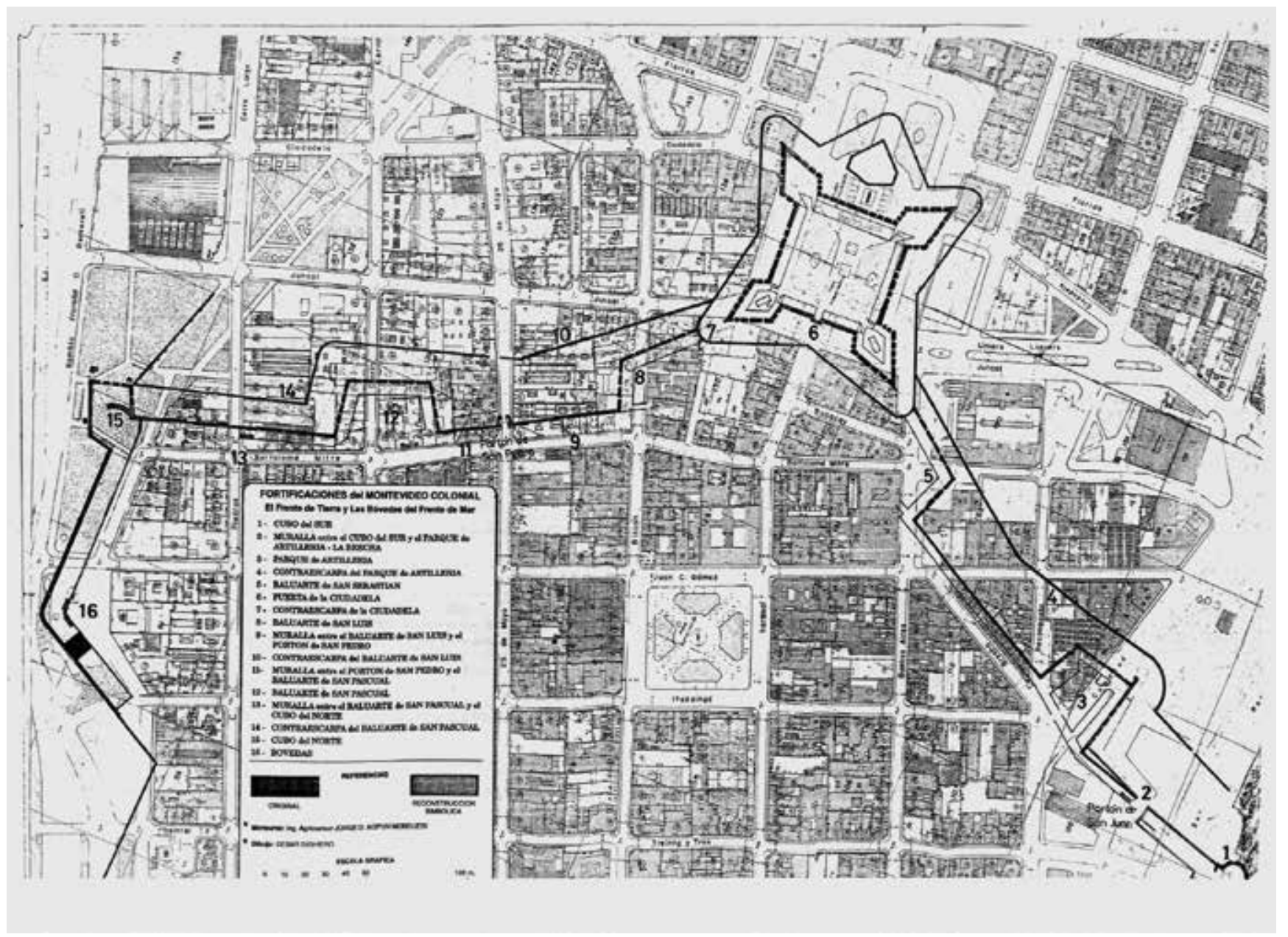


galpón principal en planta baja, eran de madera, con tirantería del mismo material, y de bovedillas de ladrillo y hierro. En este galpón, ocupando ambos niveles, había funcionado un depósito de la firma Trabucatti y, más adelante en el tiempo, una fábrica de anilinas. Como resultado de este último uso, todo el local, en ambos niveles, presentaba un avanzado deterioro, especialmente en pisos y revoques, por la acción química de las anilinas.

Tras la decisión de iniciar un proceso de conservación y puesta en valor social, la primera medida adoptada consistió en la evaluación de parte de un ingeniero químico, para obtener su opinión respecto a la recuperación de las construcciones. El mencionado profesional propuso una serie de medidas, desde el punto de vista de la higiene ambiental. Mientras tanto, el estudio de arquitectos preparaba el proyecto de consolidación de las estructuras en atención a los daños causados por el ataque de las anilinas, y las importantes cargas a las que serían sometidas con las estibas de diarios y revistas.

Antes de iniciar los estudios de consolidación estructural, se realizaron los imprescindibles cateos de todos los elementos resistentes, en especial las vigas principales de madera y los perfiles de hierro en el techo de bovedillas. Estos cateos revelaron que los elementos principales presentaban un deterioro muy avanzado, que no era perceptible a simple vista, el cual imposibilitaba que esas estructuras, aún consolidadas, pudieran soportar las cargas exigidas. Se proyectó entonces la sustitución de los techos de los locales del subsuelo por losas de hormigón armado con apoyos en vigas perimetrales.

Con el relevamiento del antiguo trazado de la muralla realizado por Baroffio, se pudo establecer que la misma debería correr paralela al frente del predio, 9 metros hacia el interior, lo cual coincidía con la pared frontal del subsuelo y, en planta baja, con la pared de separación entre los escritorios y el galpón-depósito. Hasta aquel momento, nada hacía suponer que esa pared revocada, sobre la que se apoyaban vigas de madera y hierro, que estaba atravesada por cañerías sanitarias, pudiera ser un vestigio colonial. El análisis histórico y de las edificaciones existentes permitió comprender que este lienzo de muralla colonial constituía un caso poco común en la ciudad de Montevideo, y por lo tanto se debía preservar. Así, los propietarios se avinieron a la idea propuesta por el estudio de arquitectos de concretar un proyecto que resaltara ese vestigio histórico y permitiese su observación pública, sin desatender la función principal de escritorio y depósito para la cual se había adquirido la propiedad.

El nuevo proyecto se centró en el logro de tres objetivos prioritarios:

1. Aislar la muralla para poderla observar en toda su dimensión y valor. Para ello se demolió parte del muro de separación entre los dos locales del subsuelo que dividían el lienzo y se evitó, en lo posible, apoyar las nuevas losas sobre la muralla.

2. Crear un espacio a nivel de la planta baja que permita la observación de la muralla y que al mismo tiempo sirva para la presentación de exposiciones.

3. Habilitar un nuevo acceso al subsuelo para uso del público, independiente del existente, que sería usado exclusivamente por la empresa. Este acceso permitiría, a medida que se desciende, ir descubriendo la muralla hasta llegar a un espacio multiuso, desde donde se tiene contacto pleno con el lienzo (Figura 3).

Esta doble función, de empresa y espacio cultural, se fue transformando con el transcurrir del tiempo, hasta que el destino final se ajustó a la actividad cultural. Es así que en 2004 se inaugura el espacio cultural Al Pie de la Muralla.

\section{Conocer para preservar: El involucramiento de la comunidad}

Desde sus comienzos el espacio cultural tuvo entre sus objetivos principales promover el conocimiento del pasado colonial a partir de los vestigios de las fortificaciones. Así, la educación respecto al patrimonio se convirtió en uno de los bastiones de este 
proyecto, orientada tanto a jóvenes como a adultos. Un hito en el proceso fue que el referido proyecto cultural fue declarado de interés municipal y ministerial, y en 2006 se gestionó la recolección de más de 1,000 firmas que se elevaron a la Comisión del Patrimonio Cultural de la Nación, dependiente del Ministerio de Educación y Cultural, para que el trazado de la muralla, que comprendía el frente de tierra en el Casco Antiguo de Montevideo, fuese protegido. En 2008 se comenzó a declarar monumento histórico los lugares públicos, de más fácil instrumentación, y luego se continuó con los predios privados. Para aquellos restos que no fueron declarados en un principio monumentos históricos, rige una disposición de cautela arqueológica.

Las declaraciones se realizaron por tramos. En el año 2011 un predio que pertenece al Banco de Seguros del Estado, conocido como la "barraquita", un depósito de autos siniestrados, pasó en comodato a la Intendencia de Montevideo, y se convirtió en el Espacio Muralla Abierta, que no solo alberga la mayor extensión de lienzo de muralla original (más de 60 metros), sino que es sede del Museo de las Migraciones. Al año siguiente dicho sector de la muralla se declaró monumento histórico nacional. De esta manera, el paisaje patrimonial del centro histórico se transformó paulatinamente. Actualmente, una cooperativa de viviendas, la Kolonia, se muestra muy orgullosa de haber dejado visibles restos de la muralla, situación no exenta de conflictos pues evidencia los diferentes intereses y necesidades de los diversos actores sociales e institucionales.

El sentido de pertenencia es neurálgico para el entramado de actores y los diversos intereses involucrados en la preservación del patrimonio. Muchas veces es difícil vislumbrar y construir el bien común. Para comprender estas complejidades, resulta útil el planteamiento de Latour (2008) sobre la sociedad de forma reticular, especialmente su teoría de actor en red. Esta concepción se basa en una propuesta metodológica y epistemológica que propugna estudiar la realidad desde un mapeo de las relaciones simultáneamente materiales (entre cosas) y semióticas (entre conceptos), donde las interacciones acontecidas en un fenómeno dado involucran tanto a personas como a sus ideas y a las tecnologías empleadas analizadas en su conjunto.

Latour (2008), que nutre sus ideas de los planteamientos del también francés Tarde (1843-1904), destaca la diferencia en la existencia de las cosas. Señala que solo en pocas oportunidades se producen homogeneizaciones, y estas rápidamente comienzan a destruirse, pues lo homogéneo es inestable en su interior y siempre estará compuesto por elementos rebeldes, que generaran diferencias y disconformidades de mayor o menor intensidad entre sus elementos constitutivos.

En ese sentido, se puede considerar que la categoría de patrimonio cultural se refiere a cualidades que son atribuidas a determinados bienes o manifestaciones de acuerdo a jerarquías que valorizan unas producciones y excluyen otras. Se infiere de ello que no existe lo patrimonial en sí, sino que estas categorizaciones y calificaciones son construidas socialmente. Esta construcción social de calificación que implica un proceso de patrimonialización congrega a diversos actores sociales: por un lado, los productores de calificación, tales como eruditos, agentes públicos, arquitectos, organismos especializados, entre otros; $y$, por otro, los receptores y usuarios de dichas categorizaciones, que por lo general carecen de instancias especializadas de sensibilización y conocimiento de los objetos a ser patrimonializados. En este proceso de construcción colectiva ambos tipos de actores pueden intervenir de manera pactada, conformando alianzas o tejiendo redes, o quizás también disentir poniendo en disputa ciertas categorizaciones culturales. Ambas alternativas están supeditadas, según Thompson (1993), a los contextos socio-estructurales específicos en los cuales están insertas, y a la capacidad de los individuos para crear y recrear estrategias de construcción significativas.

Los diversos grupos sociales disponen de capitales culturales disímiles, que les permiten definir su vida simbólica. Se presenta a menudo un cierto hiato entre la cultura 


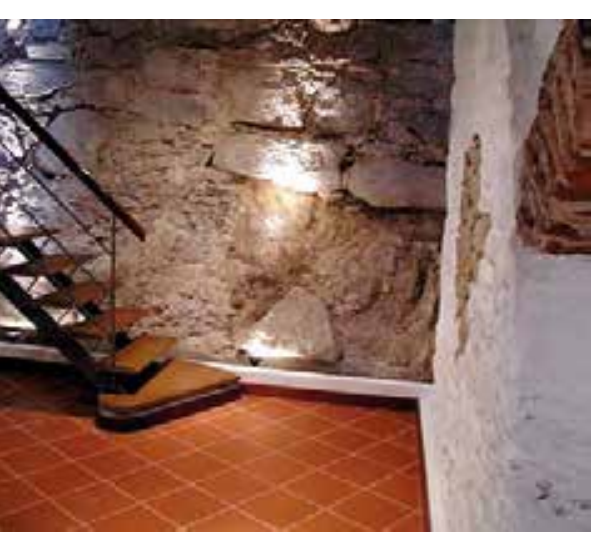

Figura 3. La puesta en valor del espacio cultural. Archivo fotográfico de la autora, 2016.

Figura 4. Calle Brecha. Tramo protegido por la Asociación de Amigos de las Fortificaciones. Archivo fotográfico de la autora, 2016.

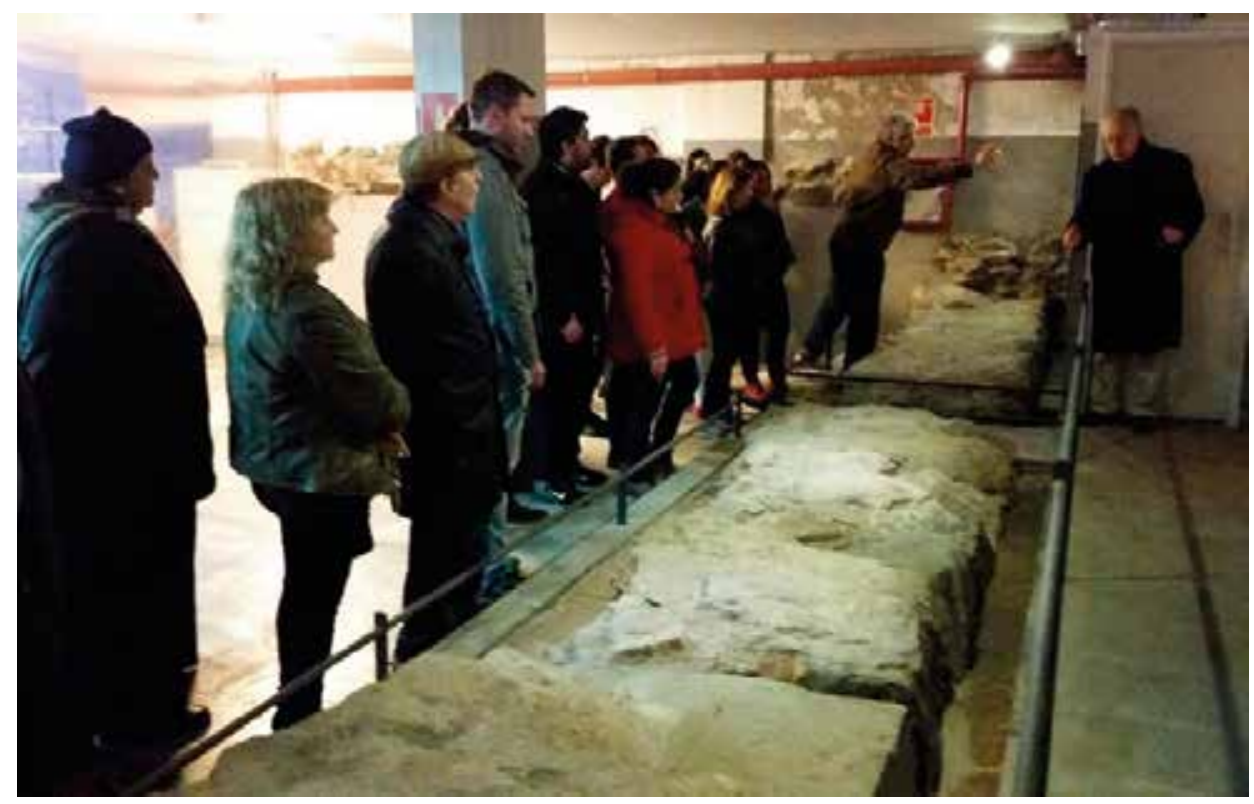

practicada y la manifestada, lo cual dificulta la inferencia de significados de la constelación de manifestaciones culturales únicamente a partir de los discursos.

Debido a las características de las manifestaciones simbólicas, el patrimonio cultural está sujeto a las necesidades de distintos grupos sociales, que a su vez se encuadran en un determinado contexto sociocultural. Es posible afirmar también que el patrimonio cultural es histórico y varía de acuerdo a los intereses de estos grupos en un transcurrir temporal cambiante. Esta diversidad que enriquece las miradas sobre el patrimonio cultural no evita la aparición de conflictos y fricciones que pueden permanecer latentes una vez que el patrimonio se institucionaliza.

De acuerdo a Thompson (1993), existen dos procesos de valoración social del patrimonio cultural: a) una valoración simbólica y b) una económica. En cuanto a la primera, la simbólica, plantea que los bienes adquieren valía en la medida en que son apreciados por la comunidad, donde la activación patrimonial está estrechamente relacionada con una demanda social de memoria y de creación de una identidad colectiva. La patrimonialización selectiva del pasado podría contemplar los siguientes propósitos: a) contribuir a la memoria colectiva y la identidad de los grupos sociales, b) destacar a través de determinados bienes ejemplares la cultura de conjunto y c) acrecentar la admiración frente al patrimonio ajeno. Dicho proceso de patrimonialización conduce a un segundo proceso de valoración social: el económico.

La activación patrimonial puede comprender una valoración económica en tanto los bienes culturales son concebidos como intercambiables en un mercado. Así, la mayor vinculación del mercado en el ámbito de producción y circulación cultural ha visibilizado la preeminencia de lo económico por sobre lo simbólico, al punto que se acrecientan las visiones negativas con respecto al turismo de masas en las zonas de patrimonio mundial. Por otra parte, se evidencian también movimientos de las comunidades locales, como el presente ejemplo, que contrabalancean en cierta forma esa lógica del mercado.

En el caso que aquí se presenta, un grupo de actores sociales se tornó decisivo en el proceso de patrimonialización: la Asociación de Amigos de las Fortificaciones, creada en 2012, dedicada a 
...el estudio, investigación, difusión, preservación, puesta en valor y educación en el conocimiento histórico, arqueológico, técnico y patrimonial de las fortificaciones, de los sistemas defensivos y de la arqueología histórica,... [pudiendo promover] cursos, cursillos, seminarios, talleres, simposios, congresos, publicaciones, medios informáticos, viajes temáticos y todo tipo de actividades educativas. (Actas de creación, p. 1)

Esta asociación ha desempeñado un rol fundamental, pues impidió que en la construcción de una obra se demoliesen más de 13 metros de lienzo para construir un estacionamiento. Hoy, aunque pertenece a un espacio privado, el segmento de muro se puede observar en el subsuelo de un edificio de la calle Brecha. Por otra parte, dicha asociación promueve y apoya acciones de divulgación, como la exposición itinerante Las Vidas detrás de las piedras. Algunas biografías de ingenieros militares, y también la organización de Congresos como el organizado por el Consejo Internacional de Fortificaciones (ICOFORT) celebrado del 3 al 8 de octubre de 2016 en Uruguay. Esta asociación tiene, desde el punto de vista sociológico, el carácter de grupo de presión ante las autoridades nacionales en lo concerniente a las acciones de conservación y preservación de las murallas como objeto patrimonializable (Figura 4).

En síntesis, es posible afirmar que el objeto muralla pasó de ser historia olvidada a un objeto de deseo:

- 2004 - Desconocimiento

- 2006 - Recolección de firmas - Al Pie de la Muralla

- 2012 - Declaración de Monumento Histórico Nacional, 1er tramo

- 2015 - Declaración de Monumento Histórico Nacional, 2do tramo

\section{¿Cómo se piensan los bienes que pueden ser patrimoniales?}

El territorio que forma parte del itinerario patrimonial a recorrer se extiende por 800 metros u ocho "cuadras" en el extremo este del casco histórico montevideano. Cada sociedad, en su contexto histórico particular, decide qué considera un objeto patrimonial. Esto significa que un bien, para que sea considerado patrimonio, necesita contar con un valor agregado, o ser objeto de una puesta en valor, en tanto medida inicial que implicaría una jerarquización de los elementos patrimoniales y, en segundo término, de una activación patrimonial, que consiste en la construcción de discursos basadas en un saber científico (Prats, 1997). Ambos procesos se nutren del consenso entre los diversos actores sociales, tanto públicos como privados; este proceso muchas veces resulta difícil, porque los tiempos e intereses pueden ser disímiles. En otras palabras, el territorio puede ser ámbito de conflictos y de disputas por el poder (Mançano, 2005). Resulta importante y atractivo re-pensar esta franja de territorio montevideana como una suerte de palimpsesto, aquel antiguo documento que se reinscribía constantemente a lo largo de diversas épocas históricas, pues estaba en permanente cambio, afectado tanto por procesos "naturales" como sociales (Corboz, 2001).

Así, los recorridos históricos culturales propuestos pretenden ayudar a la ciudadanía a disponer de elementos teóricos que les permitan leer la realidad con otros lentes y comprender la proyección del presente en el futuro. Para ello se imaginaron y pusieron en juego diversos dispositivos: narraciones, animadores sociales, música, mapas y láminas que ayudan a conformar un relato que estimula los diversos sentidos de los visitantes, conjugando lo emotivo con lo cognitivo sin descuidar el lado lúdico, siguiendo la premisa de que se aprende mejor aquello que se vivencia con disfrute.

El recorrido por los restos de fortificaciones conservados supone una musealización de la ciudad, que se procura llevar a cabo mediante una propuesta que permita seguir profundizando en el fortalecimiento de la ciudadanía y en el conocimiento de una ciudad a través de sus vestigios más antiguos. Pensar la forma en que esta propuesta cultural podía ensamblarse con una actividad turística demandó esfuerzos, 
puesto que el maridaje cultura-turismo no tiene aún un fuerte arraigo en el medio académico-profesional del patrimonio uruguayo. La gestación del producto turístico se basa en el aumento notorio del público asistente a las diversas actividades a través del tiempo, que además busca desarrollarse en un mercado no muy propenso a este tipo de productos. El principal objetivo institucional fue transformar las visitadas guiadas en producto turístico, sin perder el rigor histórico, al tiempo que se asegura la auto sustentabilidad y la generación de ingresos que garanticen la permanencia del espacio cultural, tomando en cuenta el interés, incluso misterio que genera el tema de las fortificaciones, debido en parte a un gran desconocimiento del mismo.

Entonces, ¿cómo se entiende el producto turístico? Para aproximarse a este tema empleamos diversos referentes:

Producto es cualquier cosa que se puede ofrecer a un mercado para la atención, adquisición, el uso o el consumo para satisfacer a un deseo o una necesidad (...); cada componente o combinación de componentes del destino (turístico) (en cuanto a Producto Turístico Global) pueden concebirse como un Producto Turismo Específico en el mismo. Este Producto Turístico incluye objetos físicos, servicios, sitios, organización e ideas. (Programa de Mejora de la Competitividad de los Destinos Turísticos Estratégicos, 2011, p. 21)

...es una combinación de prestaciones e infraestructuras que los turistas consumen en pos del logro de algún beneficio,... [Pero] Para que existan productos, como primera medida necesitamos recursos. Pero para que los mismos se transformen en ofertas, junto con ellas resulta imprescindible que se visualicen sus atributos, existan la voluntad y capacidad de aprovecharlos, y además se detecte la voluntad y capacidad de consumirlos. (Capece, 2008, p. 22).

\section{Educar la mirada para valorar el patrimonio}

Las propuestas educativas dirigidas a las jóvenes generaciones, tanto las visitas guiadas como la obra de teatro, responden a un esquema de educación no formal, y se basan en potenciar la sensibilidad como forma de posibilitar la construcción de una ciudadanía plena, placentera y con espíritu crítico. Ya desde fines del siglo XX, la Organización de las Naciones Unidas para la Educación, la Ciencia y la Cultura (UNESCO) definía la educación, desde una perspectiva amplia, como un proceso que tiene lugar a lo largo de toda la vida, así como un instrumento que permitirá alcanzar los ideales de paz, libertad y justicia social, que los ciudadanos aprendan a través del diálogo a vivir con sus diferencias (Delors, 1999). En ese sentido, la educación en patrimonio o educación patrimonial adquiere importancia como anclaje en una época en la que convive una sociedad marcada por lo inmediato, lo presente y lo efímero, que gira en torno al espacio y dimensión individual inserto en una dinámica global (Lipovetsky, 1996), y a su vez que demanda la reivindicación de lo local mediante una reafirmación de las identidades.

Resulta operativa la definición de García Valecillo (2009) de la educación patrimonial como

...el proceso pedagógico centrado en las percepciones, conocimientos y valores que subyacen en una sociedad. De esta manera, el bien patrimonial se convierte en un recurso para el aprendizaje, capaz de conectar al ciudadano con su diversidad cultural y su entorno social. (p. 274)

Según este esquema, el diseño de programas y acciones de educación debe tener como centro a las personas y no al bien cultural; se debe trabajar en torno a los valores culturales próximos a ellas para llegar así a los valores universales. El modelo de aprendizaje que subyace estos planteamientos está basado en la construcción activa del conocimiento en torno al patrimonio, enfocado en la comprensión e interpretación de este desde una perspectiva del aprendizaje situado en un contexto real, de forma dialógica. 


\begin{tabular}{|c|c|c|}
\hline Dimensión & Propósito & Acciones \\
\hline \multirow{4}{*}{ Conocer } & Generar procesos de aprendizaje & \multirow{4}{*}{$\begin{array}{c}\text { Abordaje integral para promover aprendizajes } \\
\text { significativos }\end{array}$} \\
\hline & Científicos académicos & \\
\hline & Vivencias & \\
\hline & Conocimientos populares & \\
\hline Comprender & $\begin{array}{l}\text { Entender los usos, significados y dinámicas sociales que } \\
\text { denotan los bienes patrimoniales en una comunidad }\end{array}$ & $\begin{array}{l}\text { Develar las tramas sociales que ha mantenido el } \\
\text { patrimonio a lo largo de la historia. }\end{array}$ \\
\hline Valorar & $\begin{array}{l}\text { Conformar una ciudadanía responsable por los bienes cultu- } \\
\text { rales en lo relativo a su sustentabilidad }\end{array}$ & $\begin{array}{l}\text { Identificar y desarrollar competencias para una ges- } \\
\text { tión ciudadana participativa }\end{array}$ \\
\hline Actuar & $\begin{array}{l}\text { Intervenir individual o colectivamente para la preservación } \\
\text { de los bienes patrimoniales }\end{array}$ & Desarrollar las competencias necesarias \\
\hline
\end{tabular}

Según García Valecillo (2009), la educación patrimonial debe abordarse desde cuatro dimensiones pedagógicas: i) conocer, ii) comprender, iii) valorar y iv) actuar, entendidas estas como espacios de referencia para la sistematización de los contenidos y estrategias educativas según los escenarios a implementar. De esta forma, las dimensiones pedagógicas estarían actuando de forma transversal a las mismas y al propio proceso educativo. A su vez, las dimensiones y las áreas se retroalimentan a partir de las experiencias de los participantes, generadas fundamentalmente a partir de un aprendizaje dialógico entre ellos.

Las dimensiones pedagógicas que plantea García Valecillo se correlacionan con los pilares de la educación propuestos por UNESCO (Delors, 1994). La primera dimensión, conocer, implica generar procesos de aprendizaje basados en los conocimientos del patrimonio cultural que irían desde los científicos-académicos hasta las vivencias y conocimientos populares. Es necesario un abordaje integral, desde varias disciplinas, que permita generar aprendizajes significativos. La segunda dimensión, comprender, enfatiza los usos, significados y dinámicas sociales que denotan los bienes patrimoniales en una comunidad. Por lo tanto, la praxis educativa debería orientarse a ayudar a los aprendices a develar las tramas sociales que ha mantenido el patrimonio a lo largo de la historia. La dimensión de valorar consistiría entonces en ayudar a conformar una ciudadanía responsable por los bienes culturales, en lo relativo a su sustentabilidad. Las actividades educativas deberían estar centradas tanto en visualizar posibles caminos para una gestión ciudadana participativa, como en identificar y desarrollar las competencias necesarias para llevarlo a cabo.

La cuarta dimensión, actuar, implica poder desarrollar las competencias requeridas para una gestión patrimonial, para intervenir individual o colectivamente en la preservación de los bienes patrimoniales. Ello se traduce en acciones específicas de capacitación en destrezas u oficios, en cualquiera de los ámbitos de actuación: formal, informal o no formal. Queda claro que existe un alineamiento entre las dimensiones, los propósitos de las mismas y las acciones para llevarlas a cabo para abordar la educación patrimonial (Tabla 1).

El alineamiento referido entre dimensiones, propósitos y acciones a emprender coincide con la línea de pensamiento propuesta en el libro Sens du Patrimoine de la Fonda- 
tion Roi Baudouin, donde justamente se destacan los siguientes objetivos de la educación patrimonial:

- Desarrolla una aproximación sensorial al patrimonio: educación de la mirada, del oído, del tacto, etc.

- Suscita una interrogación y fomenta la curiosidad.

- Desarrolla métodos comparativos y espíritu crítico.

- Favorece la expresión y la transmisión de las emociones y de los conocimientos.

- Desarrolla una competencia comunicativa para transmitir las ideas a través de la creación.

- Educa para la diversidad cultural, en la tolerancia y el respeto mutuo.

- Estimula el descubrimiento de los medios y de las nuevas tecnologías de la comunicación. (Calbó et al., 2011, pp. 97-98)

La manera en que están planteadas las visitas al espacio cultural Al Pie de la Muralla valora al territorio recorrido como parte de una ciudad que puede ser fuente de educación y contiene un entramado cultural sujeto a un pasado histórico. La musealización del espacio que se propone tiene su sustento teórico en la definición del museo como un ente comunicador, y a la vez conformador de identidad y ciudadanía, como señala Olaia Fontal:

Por tanto, cuando hablamos de museos conformadores de identidades, nos referimos a museos cuyo potencial educativo y social -en tanto que agentes dinamizadores e integradoreses tan amplio y comprometido que están generando formas de ser y de comportarse, gustos y preferencias culturales, están configurando ciudadanos sensibles y activos, son generadores de identidades patrimoniales, en definitiva. Hablamos de museos que son espejo de una realidad social, porosos a lo que sucede actualmente en el mundo, sensibles a los cambios culturales. Museos que entienden que, si contienen patrimonio, este no puede ser entendido como tal si no existe un público que se sienta identificado con él, que desarrolle un sentimiento de propiedad simbólica y de pertenencia a un grupo a través de él. (2004, p. 49)

\section{Montevideo y su obligada fundación}

La Banda Oriental, región marginal del Imperio español desde su descubrimiento en el siglo XVI, fue "tierra sin ningún provecho" hasta entrado el siglo XVII, pues carecía de oro y plata, interés principal del régimen monopolista comercial imperante. Fue zona de disputa entre los imperios español y portugués. Así, el ganado -introducido en 1611 por el gobernador de Asunción, Hernandarias- convirtió los campos de la Banda Oriental en auténticas minas de cuero y de carne. La primitiva y desorganizada producción ganadera fue la primera forma de explotación económica que allí se llevó a cabo, la cual generó una interacción con el puerto, centro de un intercambio que fue ampliando sus horizontes con el contrabando y, más tarde, con el comercio legal.

A partir de esta premisa, el análisis histórico de esta región en el período colonial bien puede articularse en torno a la ecuación histórica que marcó su destino: la pradera, la frontera y el puerto. Según los historiadores Washington Reyes, Oscar Bruschera y Tabaré Melogno (1966),

Mientras que para... el mundo de la pradera, la frontera era el horizonte abierto de la tierra común y libre, para la mentalidad mercantil de Montevideo el horizonte de sus esperanzas estaba en el río y los caminos del mar, siendo la tierra -"afuera de sus murallas"- la ancha posesión de su feudal dominio,... (p. 10) 
La Banda Oriental adquiriría importancia estratégica como franja territorial en disputa por los imperios ibéricos, lo cual en cierta forma condicionó su proceso fundacional, tardío en relación a otras regiones de la América española.

Las reformas promovidas por Carlos III, más conocidas como Reformas Borbónicas, hicieron de Montevideo un puerto privilegiado para el imperio hispano. Apostadero naval español para toda la región austral de Hispanoamérica, hasta las Islas Malvinas, en 1776, fue uno de los 23 puertos habilitados por el Reglamento de Libre Comercio de 1778 y se convirtió en puerto para el comercio de esclavos africanos en 1791. El pujante comercio de intermediación que allí tuvo lugar pautó el pasaje de aldea pastoril y militar a emporio mercantil. Ya en la segunda mitad del siglo XVIII, el oficial español Francisco Millau no dudó en llamar a Montevideo "principal fondeadero del Plata", en el que destacaba el puerto por su "figura de hierro de caballo" o herradura (como se citó en Giménez Rodríguez A., 2003, p. 40). Dada su importancia estratégica, era fundamental fortificarlo.

\section{El sistema fortificado}

Los portugueses, en su afán de expansión hacia el Sur, querían llegar a lo que entendían como las fronteras naturales del Río de la Plata. Ya en 1680 habían fundado la CoIonia de Sacramento, que estaba a cargo de Manuel de Lobo. Luego, hacia el año 1723, comenzaron a explorar la bahía de Montevideo con el fin de fundar una ciudad. Una expedición marítima proveniente del Brasil al mando de Freitas Fonseca ingresó en el puerto natural de Montevideo. En el marco de esta situación, cuando la Corona española supo de ese descubrimiento, el Rey de España Felipe $V$ ordenó al gobernador de Buenos Aires, Bruno Mauricio de Zabala, fundar una ciudad a modo de fuerte militar.

En enero de 1724, los españoles finalmente expulsaron a los portugueses, dando por terminada una serie de disputas sobre los territorios del Plata. El 25 de marzo se procedió a construir algunos edificios y las fortificaciones de lo que sería la ciudad de Montevideo. En ese mismo año llegaron las primeras familias provenientes de Buenos Aires, con el propósito de poblar la nueva ciudad. A este proceso migratorio se sumó, entre los años 1726 y 1729, la llegada de nuevas familias procedentes de las islas Canarias. El 1 de enero de 1730, Zabala designa los miembros del cabildo, dando por culminado el proceso fundacional.

Apenas ocupada la bahía de Montevideo a fines de 1724, Zabala, responsable de constituir el nuevo poblamiento, ordenó levantar una batería provisoria de seis cañones, la de San Felipe, que luego se transformaría en el Fuerte San José; y un fuerte donde más tarde se erigió el Fuerte de Gobierno (actual ubicación de la Plaza Zabala). La mano de obra para estas construcciones fue proporcionada por 1,000 indios tapes venidos de las misiones, que ejecutaron el diseño del ingeniero Domingo Petrarca, que también proyectó la primera urbanización. Aquellas fortificaciones montevideanas antecedieron a la ciudad como el ganado vacuno había precedido al colono. Fueron construidas tanto para defender la bahía de la amenaza de potencias extranjeras como para asegurar el dominio del territorio y salvaguardar los intereses económicos que en la Banda Oriental habían surgido. En aquel momento, la amenaza indígena fue grande; se temía que la novel población corriera igual suerte que la primera fundación de Buenos Aires, frustrada en 1536.

A partir de estas situaciones de origen es posible explicar las dificultades para encarar la construcción, entonces titánica, de la muralla alrededor del novel caserío. Diego Cardozo, sucesor de Petrarca, fallecido en 1736, inició esta obra, con la Ciudadela como principal edificación, acortando el proyecto propuesto por su antecesor por razones económicas. Esta no estaría ubicada en las inmediaciones de las actuales Avenida 18 de julio y Río Negro, sino en su ubicación presente, ocupando media Plaza Independencia de la actualidad (Figura 5). 


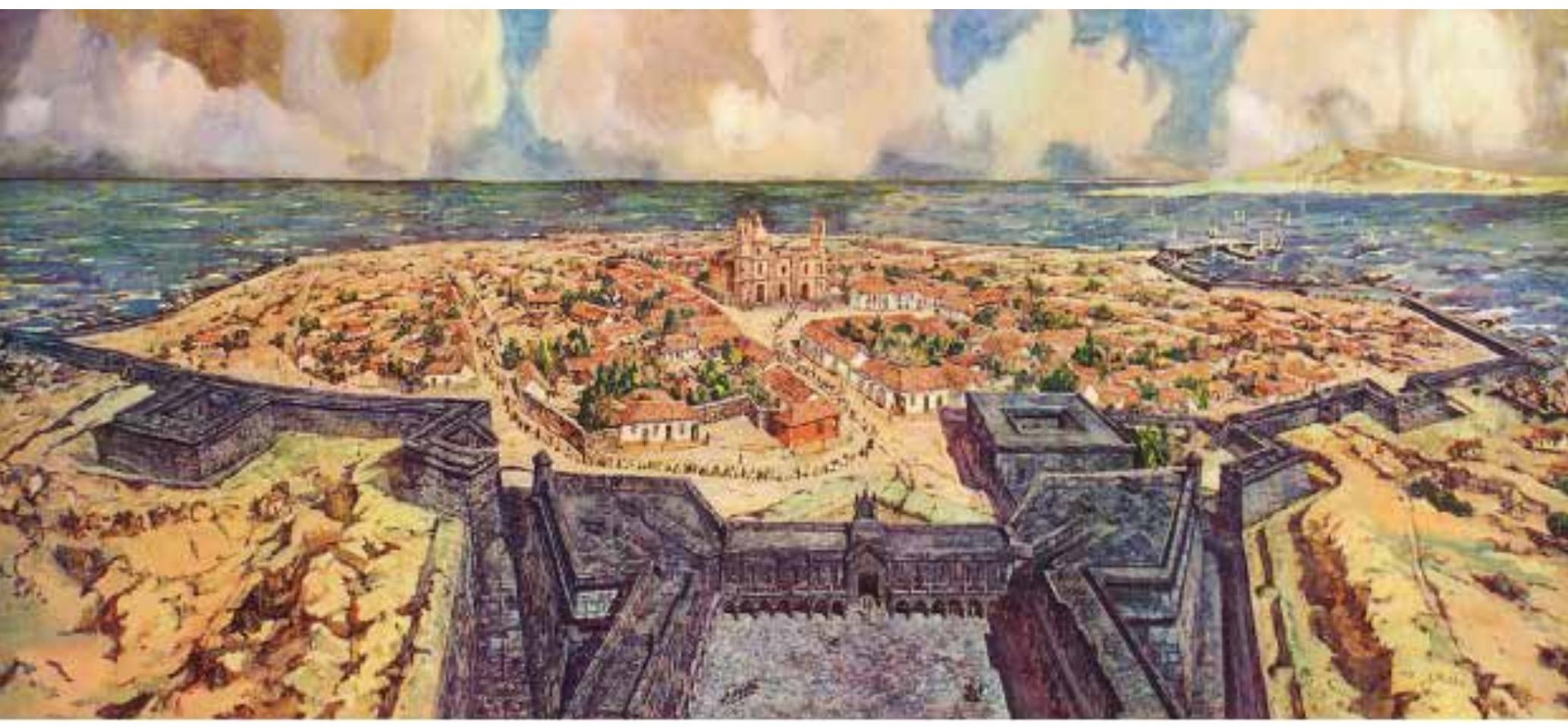

Figura 5. Montevideo fortificado en el siglo XVIII según el grabado de Leoni Mathis. Museo Histórico Nacional, s/f.
En octubre de 1741 se colocaron las primeras piedras de la Ciudadela, pequeño fuerte conectado con la ciudad por la Puerta, que restauraciones mediante se encuentra hoy en su sitio original aproximado. Esta constaba de cuatro baluartes con influencias del modelo constructivo que el ingeniero militar Sebastián Le Preste, más conocido como Mariscal Vauban, había ideado combinando "los métodos italianos del siglo XV con las experiencias holandesas del siglo XVIII" (Wagner, 2010, p. 10) (Figura 5).

De la Ciudadela partían, en forma oblicua hacia ambas orillas, donde se ubicaba el trazado de calles, las líneas de murallas que constituían el frente de tierra. Estas encerraban a la aldea colonial y condicionaban su vida. Las murallas remataban al Norte y al Sur con sendas baterías defensivas de forma semicircular, llamadas "cubos". Cada determinada cantidad de metros, baluartes y baterías reforzaban la línea de defensa en torno a todo el perímetro de la península.

Se ingresaba al recinto fortificado por dos portones: el de San Pedro, el primero erigido y por eso llamado "viejo" (hoy esquina de 25 de Mayo y Bartolomé Mitre), y el de San Juan, cerca de la esquina, a pocos metros de la actual ubicación del Templo Inglés, en la actual Rambla Sur.

Durante la invasión inglesa de febrero de 1807, la muralla fue perforada donde hoy la calle Brecha es testimonio de ese momento histórico, cuando se emplearon cueros para cubrir el orificio. Luego de otras ocupaciones sucesivas (bonaerense, patriota, portuguesa y brasileña), tras el fin de la guerra de Independencia y comienzos de la vida autónoma del Uruguay, en 1829 se demolió gran parte de las murallas montevideanas -porque se consideraba que la ciudad confinada debía expandirse- y la Ciudadela fue transformada en mercado. Otra vez, se estableció el vínculo entre la producción y la fortificación.

Cuando las murallas caen, en un diario de 1829 se afirma que "Al fin desaparecerá ese monumento que sólo ofrecía a la imaginación recuerdos ominosos", y que era "una especie de dique que tenía como represa el progreso de la población de Montevideo" (Castellanos, 1971, como se citó en Giménez, 2003, p. 60). El prócer José Artigas había querido derribarlas en 1816, pero su intención no se materializó. Tras la demolición la 


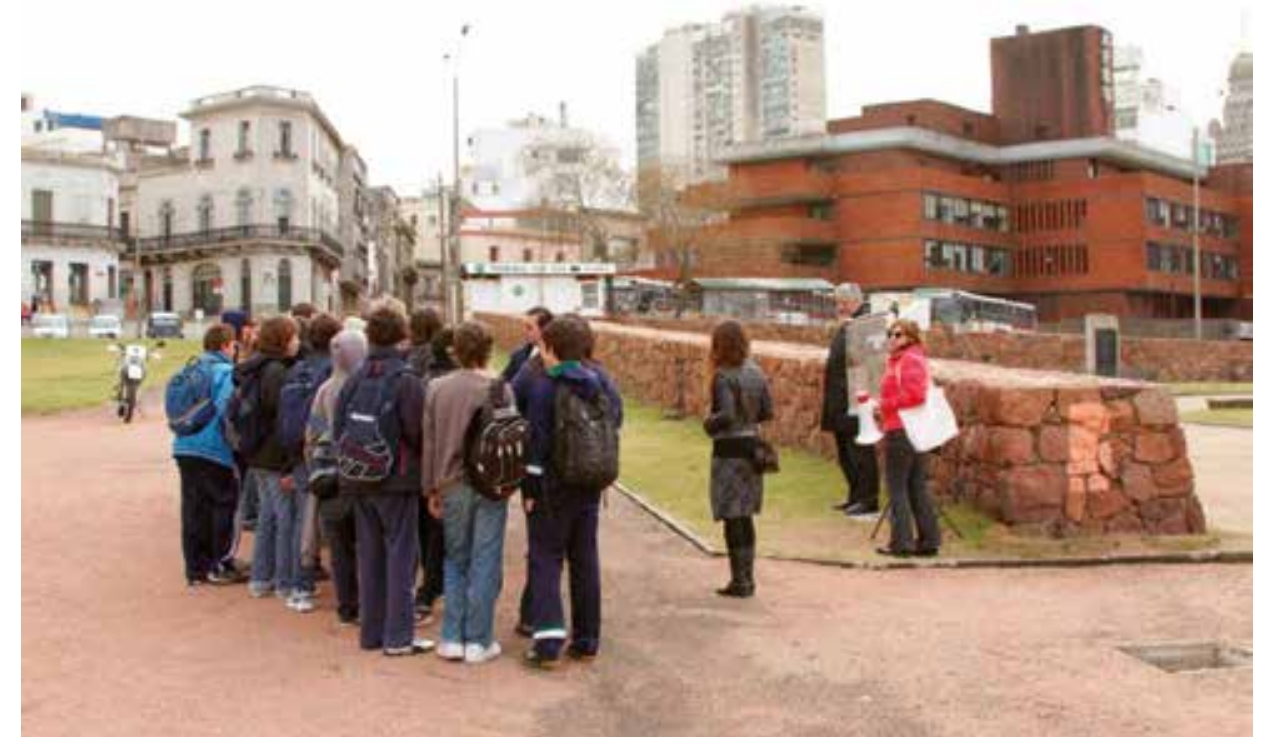

ciudad, liberada del corsé que le impedía crecer, empieza a buscar nuevos horizontes y genera su primera expansión.

En 1876 las ruinosas señales de un pasado colonial desaparecieron definitivamente, al demolerse la antigua Ciudadela para ampliar la Plaza Independencia. Dos años más tarde también se demolería el Fuerte San José. La Puerta de la Ciudadela fue desarmada para ser instalada en la sede de la Escuela de Artes y Oficios, de donde se retiraría para reubicarla en su lugar original recién 80 años después, en 1959.

Hacia mediados del siglo XX se realizaron algunas restauraciones, como la del Cubo del Sur, así como reconstrucciones simbólicas (Cubo del Norte y la Puerta de la Ciudadela): el tema de las fortificaciones parecía haber reflotado. Sin embargo, no es hasta el siglo XXI que la comunidad visualiza, conoce y se apropia de la muralla

\section{La pertenencia a redes}

El espacio cultural Al Pie de la Muralla integra el Montevideo Bureau, asociación civil que se dedica a promover la capital uruguaya como destino turístico. La mesa de trabajo de museos de dicha asociación organiza Montevideo+Museos, red cultural compuesta por más de 40 museos montevideanos pertenecientes a diversas dependencias estatales, así como privados. En mayo de 2016 se realizó la 4ta edición, centrada en el Día Internacional de los Museos. Incluyó propuestas de actividades diversas, orientadas a promover transversalidad entre los actores y las acciones. Además, participa del Día del Patrimonio, que se celebra en mayo de cada año, y de Museos en la Noche, evento convocado por el Ministerio de Educación y Cultura cada diciembre.

\section{La patrimonialización del territorio: La debida alianza cultura y turismo}

Desde hace más de una década que el espacio cultural Al Pie de la Muralla desarrolla acciones de difusión de los restos del sistema fortificado montevideano. Así, dirigen sus acciones a hacer conocer estos vestigios de las murallas mediante el instrumento más poderoso que posee una sociedad: la educación. En ese sentido, se elaboraron propuestas para la ciudadanía, considerando dos públicos clave: a) las jóvenes generaciones y b) los adultos jubilados. Dirigirse al primer grupo es vital para que pueda
Figura 6. Visita tras la muralla perdida, en el Parque de Artillería Cubo del Sur. Archivo fotográfico C. Yáñez, 2016. 
conocer lo desconocido y pensar en acciones futuras de conservación, mientras que el segundo necesita acciones de dispersión y goce al tiempo de conocimiento histórico.

Así, se ofrecen varios productos culturales: visitas guiadas tanto dentro como fuera del espacio cultural, así como obras de teatro para los escolares.

Visitas en territorio (Figura 6):

- De Cubo a Cubo', que cuenta con animadores sociales y música para todo público

- Las Fortificaciones Invisibles, narración para todo público

- Los Secretos de la Muralla, narración para escolares

- Tras la Muralla Perdida, que cuenta con animadores sociales y música para adolescentes

- Las Murallas bajo las Antorchas, visita nocturna para todo público

Visitas dentro del espacio cultural AI Pie de la Muralla:

- Montevideo Intramuros, narración y música para todo público

Obra teatral

- Montevideo la Propia Muralla, para escolares de 6 a 12 años

En la actualidad, la oferta turístico-cultural del espacio Al Pie de la Muralla permite observar el trazado de la antigua muralla superpuesta a la trama actual y los puntos donde se encuentran vestigios fortificados, tales como (Figura 7):

1) Las Bóvedas (salida) (Rambla 25 de Agosto y Juan Carlos Gómez)

2) Cubo del Norte (reconstrucción simbólica)

3) Muralla entre el Baluarte de San Pascual y el Cubo del Norte; y Contraescarpa del Baluarte de San Pascual (espacio cultural Muralla Abierta)

4) Espacio cultural Al pie de la Muralla (Bartolomé Mitre 1464)

5) Portón de San Pedro (cruce de calles 25 de Mayo y Bartolomé Mitre).

6) Baluarte de San Luis (Antiguo local de la empresa Lancer y Consejo de Educación Secundaria)

7) Puerta de la Ciudadela

8) Baluarte de San Luis (Bartolomé Mitre y Buenos Aires)

9) Contraescarpa del Parque de Artillería (Reconquista y Juan Carlos Gómez)

10) Parque de Artillería (Plaza España)

11) Portón de San Juan (Plaza España)

12) Cubo del Sur (Rambla sur)

El propósito principal de las vistas guiadas es que los participantes puedan ver, tocar e imaginar las murallas coloniales, y así re-significar el pasado al mirarlo a través de los ojos del presente. En palabras de una señora que ha realizado uno de los paseos ya tres veces: "Ahora puedo mirar lo cotidiano de la ciudad de manera diferente. Puedo ver lo que antes no veía porque comprendo muchas cosas que ignoraba" (comunicación personal, s/f). Esta visita, así, cumple con el objetivo de hacer visible lo cotidiano para el turista nacional y hacer conocer nuestro pasado interpelado por nuestro presente al visitante extranjero.

1. El cubo es un elemento arquitectónico con forma de balde o cubo invertido que remataba la doble línea de murallas en ambos extremos de las mismas, en el Norte y en el Sur de la península montevideana que hoy constituye la Ciudad Vieja. 


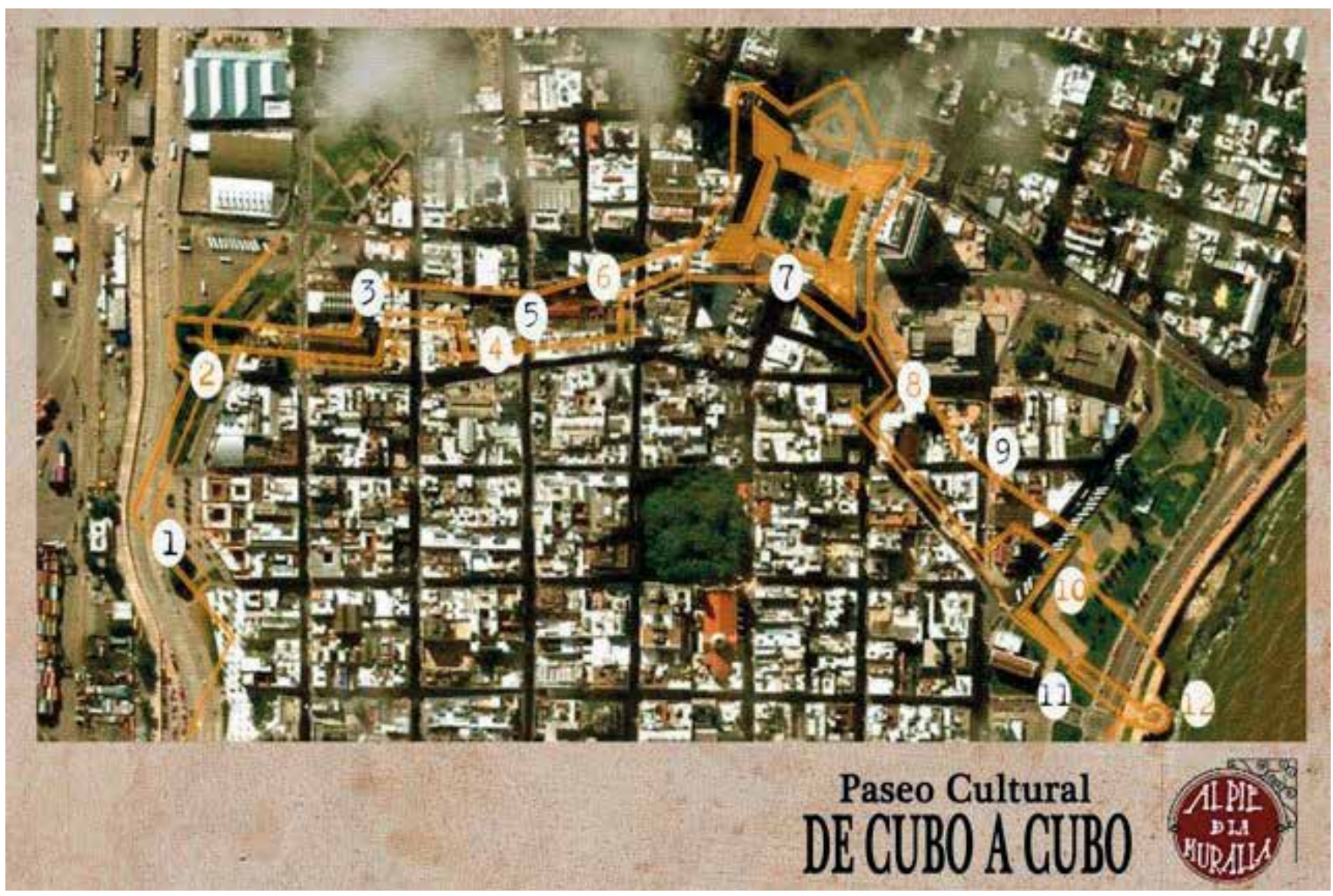

\section{A modo de cierre para nuevas aperturas}

En suma, transformar un bien en objeto patrimonial requiere un proceso de involucramiento de actores que representan los intereses de la comunidad, así como de un proceso de educación patrimonial, entendido como un proceso educativo permanente y sistemático centrado en el patrimonio como fuente primaria de conocimiento, y enriquecimiento individual y colectivo, que a la vez debe actuar como instrumento de alfabetización cultural que permite a la persona interpretar el mundo que le rodea y guiar sus intervenciones (Teixeira en Cantón Arjona, 2009).

En el caso particular aquí tratado, si bien los visitantes muestran reacciones de regocijo al contemplar los restos de muralla, ello no significa que el objeto patrimonial en cuestión hable per se, sino que la presencia y el trabajo de los mediadores y comunicadores es fundamental para que el receptor construya su propia trayectoria de aprendizaje.

Si se quiere que el visitante disfrute y comprenda, se torna imperioso crear un escenario habilitador con una fuerte potencia comunicativa. Diseñar esta mediación interpretativa requiere comprender los mecanismos de aprendizaje del receptor, para que se produzca una relación significativa entre el mensaje que se pretende enviar y la realidad individual del visitante, realidad que presenta una naturaleza bifronte entre el deseo de preservar el patrimonio y la globalización con sentido uniformizador que cada vez más se impone.

Visitar y educar en patrimonio resulta un buen maridaje, que provoca la emoción en el visitante y una vivencia significativa; como sostiene Lombardi (2015), “Los nuevos pro-
Figura 7. Recorrido por el trazado de la muralla. Espacio cultural AI Pie de la Muralla. Fuente: Archivo fotográfico de la autora, 2016. 
ductos turísticos relacionados con la oferta cultural deben generar una experiencia en el visitante, para ello la autenticidad, la estética y la sustentabilidad pasan a ser valores insoslayables del objeto y su entorno". Conocer y visitar el patrimonio es una forma de hacer visible lo cotidiano, desde un presente abierto a la diversidad cultural, a las diferentes racionalidades y a la identidad, una identidad ciudadana inclusiva, dialógica, crítica y con proyección de futuro.

Como reflexión final, de modo general, puede afirmarse que resulta claro y necesario que se debe apostar por la interacción de patrimonio, turismo y educación en un proceso que permita alcanzar la revalorización del pasado y la generación de un producto histórico cultural sostenible, cualidad vital para lograr la sustentabilidad de propuestas culturales de gran potencial en un mundo que es cambiante pero a la vez clama por anclajes de su memoria.

\section{Referencias}

Baroffio, R. (1994). El rescate de las Murallas de Montevideo. Apartado del Boletín Histórico del Ejército, (pp. 287-290).

Calbó et al. (2011). Sens du Patrimoine. Bruselas, Bélgica: Fondation Roi Baudouin.

Cantón, V. (2009). La educación patrimonial como estrategia para la formación ciudadana. Correo del Maestro, (p. 154).

Capece, G. (2008). Turismo, la esencia del negocio. Buenos Aires, Argentina: Cencage Learning.

Castellanos, A. (1971). Historia del desarrollo edilicio y urbanístico de Montevideo 1829-1914. Junta Departamental de Montevideo, Biblioteca J. Artigas, Montevideo.

Corboz, A. (2001). El territorio como palimpsesto. En A. Corboz (Coord.), Le territoire comme palimpseste et autres essais (pp. 15-36). París, Francia: Besançon.

Delors, J. (1994). La educación encierra un tesoro. Madrid, España: Santillana.

Fontal, O. (2004). La educación patrimonial: Teoría y práctica en el aula, el museo e Internet. Barcelona, España:Trea.

García, Z. (2009). ¿Cómo acercar los bienes patrimoniales a los ciudadanos? Educación patrimonial. Un campo emergente en la gestión del patrimonio cultural. Pasos, Revista de Turismo y Patrimonio Cultural, 7(2), 271-280.

Giménez, A. (2003). Breve historia de Montevideo. Montevideo, Uruguay: El Galeón.

Latour, B. (2005). Reensamblar lo social. Buenos Aires, Argentina: Manantial.

Lipovetsky, G. (1996). La era del vacío. Ensayos sobre el individualismo contemporáneo. Barcelona, España: Anagrama.

Lombardi, O. (2015). Turismo cultural. Seminario organizado por la Cátedra de Turismo cultural de la Universidad Nacional de Lanús, Montevideo, Uruguay.

Mançano, B. (2005). Movimentos socioterritoriais e movimentos socioespaciais. OSAL, año VI(16), junio, 273-283.

Programa de Mejora de la Competitividad de los Destinos Turísticos Estratégicos. (2011). Manual de productos turísticos. Montevideo, Uruguay: Minturd BID.

Prats, L. (1997). Antropología y patrimonio. Barcelona, España: Ariel.

Reyes W., Bruschera O., \& Melogno T. (1966). Banda Oriental. Pradera, frontera y puerto. Montevideo, Uruguay: De la Banda Oriental.

Thompson, J. (1993). Ideología y cultura moderna. Teoría crítica social en la era de la comunicación de masas. México DF, México: Universidad Autónoma Metropolitana, Unidad Xochimilco.

Wagner, A. J. (2010). Fortificaciones históricas de Valdivia. Valdivia, Chile: Universidad San Sebastián. 